\title{
Discussão conceitual sobre o mecanicismo moderno através da lógica de Hegel
}

\author{
Conceptual discussion on modern mechanicism through Hegel's logic
}

Bruno de Godoy ${ }^{1}$

\section{Resumo}

O presente artigo pretende elucidar alguns pressupostos inerentes à argumentação do Primeiro capítulo da Segunda Seção da obra Ciência da Lógica, A Doutrina do Conceito de Hegel, no que diz respeito ao mecanismo e a visão reducionista das ciências contemporâneas, utilizando como pano de fundo alguns conceitos inerentes a sistemas complexos. Para tanto, será revista a posição filosófica de outros autores sobre a percepção de mundo e a relação entre causalidade, finalismo e mecanicismo.

Palavras-chave: Mecanicismo. Complexidade. Reducionismo. Ciência da Lógica. Causalidade. Finalismo.

\begin{abstract}
This article intends to elucidate some assumptions inherent to the argument of the First Chapter from the Second Section of the Hegel's Science of Logic, Doctrine of the Concept, regarding the mechanism and the reductionist view of the contemporary sciences, using as a background some concepts inherent to complex systems. For this purpose, the philosophical position of other authors and their perception of the world and the relationship between causality, finalism and mechanicism will be reviewed.
\end{abstract}

Keywords: Mechanicism. Complexity. Reductionism. Science of Logic. Causality. Finalism.

\section{Introdução}

Segundo uma interpretação de mundo aristotélica, podemos dizer que o macrocosmo é um grande organismo, cujas partes possuem finalidades e realizam funções. A visão de mundo ocidental, surge basicamente no século XVII a partir do paradigma newtoniano, o qual defende que o universo nada mais é do que uma máquina, e suas partes interagem externamente, não havendo finalidades inerentes. Deste modo, os processos da natureza são tratados com estabilidade e apresentam, portanto, configurações constantes de fenômenos. Nesse contexto, o

\footnotetext{
${ }^{1}$ Mestrando em Administração e Negócios pela Pontifícia Universidade Católica do Rio Grande do Sul (PUCRS).

E-mail: bruno.godoy@pucrs.br
} 
papel da ciência é compreender esses arranjos por meio de leis e pela construção de modelos, que normalmente são traduzidos através de fórmulas matemáticas.

No decorrer do século XX, Albert Einstein conclui seus estudos sobre a teoria da relatividade, modificando o entendimento sobre espaço, tempo e movimento, o fato é que essa nova teoria não contraria a concepção mecânica em seus fundamentos. Os fundamentos quânticos, em contrapartida, desnortearam a noção de microcosmos, mas não a ponto de abalar a cientificidade predominante dos fenômenos que se situam além dessa grandeza (DEWITT, 2004, p. 299-305)

A contar das primícias do século XVI, verifica-se que esse modo, onde a ciência pode ser manipulada, vem se fortalecendo consideravelmente, e não apenas por ter ampliado o seu alcance ao provocar conhecimentos cada vez mais determinantes sobre certas atividades, mas também por ter expandido o seu escopo sobre outras questões da humanidade. A ciência atual pode ser considerada analítica e se caracteriza por abranger uma rede bem diferenciada de áreas onde se preconizam saberes especializados. De todo modo, há uma crítica sobre esses saberes, pois algumas vertentes de pensadores afirmam que eles não buscam qualquer sabedoria, como afirma Max Weber em sua obra "A ética protestante e o espírito do capitalismo" são apenas produções do que se passou a chamar criticamente de racionalidade instrumental.

O modo mais trivial de mudança, que é o movimento de um objeto ao se deslocar de um ponto a outro, retrata bem a cientificidade da ciência moderna. Conforme é possível observar nas formulações de Russell, esse modo de existir da matéria, entendido como fenômeno, consiste meramente na ocupação de diferentes lugares em diferentes momentos do tempo. Há movimento porque, através da ocupação sucessiva de posições em certos momentos, se estabelece uma correlação entre lugares e tempos (PRIEST, 1985, p. 339). O movimento, assim concebido, é normalmente intitulado de mecânico. Ao considerá-lo dessa forma, presume-se que o movimento ocorre no interior de um sistema natural que pode ser reduzido ou limitado, como se estivesse isolado do meio exterior e deste modo, pudesse ser analisado.

Nesse cenário, podemos dizer que o paradigma da ciência moderna é o mecanicismo, e do ponto de vista lógico, reduz-se na apresentação das ocorrências do mundo por meio de intercorrências recorrentes de estado em sistemas fechados 
(BHASKAR, 2008, p. 63-68). A física newtoniana, afirma que os fenômenos que ocorrem no mundo, são resultados dos arranjos de partículas que se encontravam em movimento de translação em um espaço e tempo, compreendidos como homogêneos e universais, e suas trajetórias seriam determinadas por sistemas dinâmicos, ou seja, conceitos como causa, força, energia e matéria foram utilizados para justificar esses fenômenos. Sendo assim, as manifestações fenomenológicas se expressam como se estivessem atadas apenas externamente, mediante leis deterministas de causa e efeito.

De acordo com o supracitado, sugere-se que o pensamento formal, compreende então, os objetos e coisas por meio da identificação de suas partes e da reconstituição do todo a partir do entendimento dessas partes. Essa premissa reducionista, que são os legados da revolução científica do século XVII já haviam sido avaliadas pelo matemático e biólogo Robert Rosen que observou:

O conceito central da mecânica newtoniana, do qual todos os outros fluem como corolários ou garantias, é o conceito de estado e, com ele, a introdução efetiva da recursão como base de sustentação da própria ciência.... Assim, na minha opinião, a obra Principia em última análise, corroborou para as mudanças mais profundas sobre os conceitos da Lei da Natureza, de certa forma, impondo-lhe as mais severas restrições e limitações (ROSEN, 1991, p.89).

\section{Sobre a ciência reducionista}

O conceito de átomo não emergiu de nenhuma análise oferecida por Newton; ao contrário, ele simplesmente pressupôs partículas sem estrutura e dedicou-se inteiramente à síntese, questionando apenas qual é o comportamento esperado dessas partículas, individualmente ou coletivamente. Não há lugar para causas finais, a única implicação é uma regra recursiva que governa a sucessão do estado da matéria. Uma relação de causalidade é feita até onde possa ser codificado em uma sequência de transição de estado, pois esse é o processo newtoniano, tudo pode ser decodificado de volta à linguagem causal.

Outras restrições seguem a partir da suposição que o universo é composto de partículas sem estrutura, que todo sistema tem um modelo maior a partir do qual qualquer outro modelo pode ser efetivamente abstraído por meios puramente 


\section{4 | Opinião Filosófica, V. 11, Dossiê - Teoria do Objeto na Lógica de Hegel}

formais, e "esse modelo maior é de natureza essencialmente sintática, em que elementos estruturais e não analisáveis (as partículas) são compelidos por regras de vinculação obrigatórias que estão fora do alcance da vinculação” (ROSEN, 1991, p.103). Com base nessa análise da ciência newtoniana, Rosen definiu um sistema natural como mecânico, que consiste em um conjunto de estados e uma regra de recursão, a qual envolve estados subsequentes dos estados atuais e todos os outros estados podem ser deduzidos do maior por meios formais.

O reducionismo prevalece não apenas porque o conhecimento científico objetivo chegou a ser identificado pela maioria das pessoas, como o conhecimento baseado nessas suposições newtonianas, mas porque essas suposições estão intimamente ligadas à maneira como todas as outras facetas da cultura são interpretadas e incorporadas na tecnologia moderna. Rosen retrada também que:

Uma vez dentro desse tipo de universo ... nós não podemos mais sair, pois todos os referenciais originais externos foram presumivelmente levados para dentro desse sistema. Sendo assim, essa tese nos garante que todos os referenciais foram internalizados de uma forma puramente sintática (ROSEN, 1999, p. 77).

É como se as pessoas na cultura ocidental, estivessem agora, encarceradas em mundos construídos com base nas suposições da física clássica, as quais norteiam o modo como eles vivem, percebem e pensam, cegando-os para qualquer modo de realidade que não possa ser compreendido a partir desta perspectiva. Corroborando com o que foi mencionado anteriormente, um artigo publicado na revista Nature em 2002 entitulado "Células como Computação" argumenta que a ciência da computação atual, pode fornecer as abstrações necessárias para uma compreensão científica da vida (REGEV E SHAPIRO, 2002).

O método reducionista da ciência moderna, estabelece que se inicie de unidades definidas por certas caracteristicas particulares, e que estão relacionadas a um determinado sistema fechado, propondo assim, uma separação entre o sistema e seu ambiente. Deste modo, haverá uma isolamento das partes que compõem o todo ou o sistema, não sendo possível uma interferência ocasionada por eventuais mudanças no ambiente. Inserida nessa perspectiva, estabeleceu-se a tese de que o universo poderia ser considerado como uma enorme máquina computacional, conforme retrata o matemático e filósofo Lloyd "imaginar que o universo não é 
apenas uma máquina, mas também uma máquina que computa, vem a ser uma extensão potencialmente poderosa do paradigma mecanicista” (LLOYD, 2010, p. 96), o fato é que essa visão de mundo ignora totalmente as limitações do mecanicismo.

\section{Princípios da complexidade}

Quando se fala em teoria dos sistemas complexos, é comum trazer à tona a obra Teoria geral dos sistemas, na qual Bertalanffy discorre sobre as limitações das metodologias analíticas nas investigações científicas, as quais trazem Newton, Descarte e Galileu, como seus maiores representantes. De acordo com Descartes (1983) para se conhecer a totalidade, deve-se começar pelas partes mais simples e de fácil reconhecimento, e aos poucos ir em direção ao todo, ou seja, a explicação científica dos objetos se dá através da reconstituição ou redução do todo aos componentes que o constituem, o que também é conhecido como reducionismo clássico ou mecanicismo, o que vai contra ao conceito de complexidade.

Outra idea central proposta por Descartes foi o dualismo, com o intuito de explicar como podemos entender melhor o mundo. Ele propôs que nossa mente está separada do mundo material e que essas áreas não possuem características em comum, sendo assim, não podem ser explicadas da mesma maneira. Mesmo ambas sendo uma criação divina, o mundo tinha que ser explicado, enquanto a mente fazia as explicações. O universo para Descartes era uma máquina, que se comportava de acordo com as leis e regras que governam máquinas, e se fosse possível explicar o arranjo bem como o movimento de suas partes, você poderia entendê-las, essa tese também poderia se aplicada para sistemas biológicos. Descartes afirmava que os Animais também eram máquinas e poderiam ser modelados como tal.

De acordo com o filósofo Paul Cilliers (1998) as características dos sistemas complexos, em oposição as teorias newton-cartesianas defendem a ideia de que os sistemas são abertos, estão dispostos a receber influencia do ambiente no qual eles operam, e podem também interferir no ambiente, tal abertura dificulta a inserção de barrerias entorno do sistema. Outro aspecto relevante é que cada elemento que compõem o sistema, possui uma certa apatia sobre o comportamento do sistema como um todo, desconhecendo o efeito de suas ações sobre o mesmo. A 


\section{6 | Opinião Filosófica, V. 11, Dossiê - Teoria do Objeto na Lógica de Hegel}

complexidade surge da enorme quantidade de redes de relações e interações que são resultado dessas interações locais.

Ainda conforme Cilliers (1998) a complexidade é uma caracteristica do sistema e não dos componentes que o constituem, o conhecimento sobre cada componente é limitado e local, e não há nenhum elemento que possua capacidade intrinseca suficiente para representar a complexidade do todo. Isto explica, porque o comportamento do sistema não pode ser reduzido ao comportamento de seus elementos constituintes. As interações que ocorrem nessas estruturas não são lineares, ou seja, há uma assimetria entre entrada e saída, e pequenos eventos podem ocasionar grandes resultados.

Segundo as teorias de Bertalanffy (1968) é possível verificar que o autor retrata as incapacidades do método reducionista clássico, através de dois aspectos principais, no que diz respeito a procedimentos analíticos sobre estudo de objetos compostos de múltiplas partes, o que nem sempre poderá ser obtido. A primeira discorre sobre as interações das partes, que deveriam ser suficientemente fracas ou até mesmo inexistentes a ponto de serem negligenciadas, afinal, apenas nessas condições específicas o fenômeno poderia ser compreendido como uma mera integração de suas partes. O segundo aspecto considera que a relação de causa e efeito, ou o princípio da razão suficiente, que ocorre da parte para o todo, deveriam ser lineares ou quase lineares. E somente nessas condições, haveria coerência em dizer que o comportamento do todo obedece um padrão de comportamento das partes. Conforme o referido autor, essas duas premissas dificilmente ocorrem em “ entidades chamadas sistemas, isto é, naquelas que dependem das partes em interação" (BERTALANFFY, 1968, p. 19).

A ciência moderna tende a desconsiderar qualquer noção holística, pois procura explicar os fenômenos pela redução ao absoluto, por consequência, a ciência contemporânea vem enfrentando adversidades ao tentar compreender o todo, considerando não apenas seus elementos constituintes, mas também, a maneira como eles interagem, e estão organizados no interior do sistema. Bertalanffy (1968) defende que as investigações das partes de um modo isolado, não garantem o entendimento da totalidade. 


\section{Discussão}

Se de certo modo a ciência contemporânea se tornou possível mediante a abstração de certa complexidade constitutiva do mundo, essa abstração se revelou essencial para determinadas finalidades do ser humano diante dele. Segundo o químico russo Ilya Prigogine (2003, p. 7-20) a ciência de tradição moderna não abrange o advento de complexidades inesperadas, não se importa com a flecha do tempo, e desconsidera a criatividade da natureza, nesse contexto o mecanismo pode ser visto como uma forma de se explicar a natureza.

O triunfo da ciência moderna, na concepção de alguns autores, reside no modo de compreensão do movimento. Entretanto, esse método apresenta algumas objeções conceituais, pois segundo essa visão, aquilo que se move nunca está verdadeiramente em processo de mudança, no momento em que eu o acolho, é descartado aquilo que se entende por estado de fluxo ou de passagem. Ocorre que, o movimento é representado através de uma sequência linear e infinita de lugares ou estados. De acordo com Hegel, esse modo de representação "é somente o aqui universal”, sendo que esses “aqui” não se diferem qualitativamente, ou seja, o objeto estando em um lugar ou outro, não incorrerá em diferenças, anulando a temporalidade do devir.

Em conformidade com o filósofo Graham Priest (1985) e sua obra Inconsistências do movimento Hegel afirma que para compreender o movimento, é necessário aceitar a contradição de que algo se move não porque num determinado momento está aqui e em outro não está, mas porque num mesmo momento está aqui e não está, sendo assim, o movimento em si mesmo é a existência imediata da contradição. Ao invés de ser apresentado como um encadeamento de estados, o movimento surge como uma sequência de momentos interconectados por meio de uma lógica circular de realimentação.

A filosofia da natureza de Hegel, vai contra a visão mecanicista da ciência da natureza moderna, a qual acredita que a natureza se resume a um tipo de máquina desprovida de inteligência ou de um sentido interno necessário. Esta visão mecanicista da natureza, mesmo que inserida como estágio inicial e, portanto, também necessária da filosofia da natureza de Hegel é na verdade o grande alvo da crítica hegeliana que serve de base para o desenvolvimento de seu próprio sistema 


\section{8 | Opinião Filosófica, V. 11, Dossiê - Teoria do Objeto na Lógica de Hegel}

filosófico. A crítica de Hegel ao mecanicismo moderno se expressa não através da negação pura do mesmo, mas de sua localização como o modo mais abstrato de perceber a natureza.

Evidencia-se que as ciências contemporâneas, teimam em negar qualquer conteúdo de origem metafísica, o fato é que esse tipo de postura, distancia cada vez mais a ciência moderna de uma cientificidade verdadeira, colocando-as num patamar puramente abstrato, denominado por Hegel de "representações" (Vorstellungen). A partir desse nivelamento inicial, pode-se dizer que a crítica de Hegel ao pensamento científico e filosófico modernos, refere-se a uma tendência de fixação de determinadas verdades, a ponto destas se confundirem com dogmas religiosos. Hegel critica a física na passagem de sua História da Filosofia quando fala sobre o pensamento abstrato que as vezes é tratado de um modo tendenciosamente empirista pelos cientistas modernos, e de um modo tendenciosamente matemático de se explicar os fenômenos naturais. Segundo Hegel, o pensamento concreto sobre a natureza deve cogitar a experiência, mas esta deve superar o modo puramente exterior, firmado apenas nos sentidos, a fim de mostrar-se, como um aspecto do pensamento concreto, capaz de nortear o verdadeiro conceito:

Os pensamentos na física são apenas formais pensamentos da compreensão. $\mathrm{O}$ conteúdo mais próximo, a matéria não pode ser determinada por meio dos próprios pensamentos, ela precisa, ao contrário, ser considerada a partir da experiência. Apenas o pensamento concreto contém a sua determinação e o seu conteúdo dentro de si, apenas o modo exterior do aparecer pertence aos sentidos (VGPh, p. 596)².

Neste ponto, cabe ressaltar que o mecanismo converte a relação de causalidade numa relação de determinação, ou seja, as relações causais são reduzidas a um mecanismo. As causas finais são reduzidas às causas eficientes, quer dizer, o mecanismo é o oposto do finalismo, pois os objetos são vistos como determinidades exteriormente postas. Não há finalidade no objeto mecânico, numa

\footnotetext{
22 No original: "Die Gedanken in der Physik sind nur formelle Verstandesgedanken; der nähere Inhalt, Stoff kann nicht durch den Gedanken selbst bestimmt werden, sondern muß aus der Erfahrung genommen werden. Nur der konkrete Gedanke enthält seine Bestimmung, Inhalt in sich; nur die äußerliche Weise des Erscheinens gehört den Sinnen an”.
} 
relação linear de causa e efeito, através do princípio da razão suficiente, o objeto primeiro irá determinar o objeto segundo.

De modo contrário a Kant, o qual não atribuiu fins à natureza, pois considerava o mecanicismo como único princípio de conhecimento, na medida que a finalidade não possui valor constitutivo das categorias, Hegel defendia que o mecanismo inexiste na natureza, pois lá existe somente causalidade e para que a causalidade se reduza a um determinismo, obrigatoriamente a natureza deve ser reduzida a um mecanismo.

Ao discorrer sobre o processo mecânico, Hegel retrata como "os objetos são considerados somente como totalidades", ou seja, não podem agir uns sobre os outros, comparando-os sob essa determinação com as mônodas. Ele faz uma crítica a essa visão harmônica preestabelecida, argumentando que deste modo, os objetos estariam sendo subtraídos do conceito, o mecanismo sob o ponto de vista hegeliano, é examinado através de uma perspectiva teórica, ou seja, resulta do conceito, e não de uma abordagem prática moderna. Hegel fala que: “... uma vez que a esse ser em si não corresponde o ser posto, o grau de desenvolvimento, justamente por isso esse ser em si tem seu fundamento em um outro" (HEGEL, 2018, p. 191). Esses aspectos anteriormente citados, podem ser vistos como uma crítica a apatia dos elementos de um sistema, pois a ideia de que não haveria interação entre os objetos de um conjunto é superficial, afinal, um elemento é fundamentado em um outro, ou seja, há interação entre as partes.

À sombra da filosofia da natureza de Hegel (1997), constata-se que o pensamento conceitual pode suplantar a compreensão encontrada na universalidade constitutiva do ser, havendo compreensão da composição das partes num todo, isto é, elaborando o conceito daquilo que fora antecipadamente analisado. O conceito observa as diferenças determinadas, mas concebe tudo em suas relações externas e internas, tornando toda existência numa totalidade existencial. Conforme a ordem do conceito, o ser como totalidade, pode ser considerado como um processo de transmutação que possui uma lógica própria.

\section{Conclusão}

Ao pensarmos o mundo, o pensamos entorno de uma base racional, através 
de padrões, leis ou qualquer linguagem compreensível, batalhamos para tornar essa racionalidade "verdadeira". E no anseio dos grandes construtores de sistemas filosóficos, seja de Descartes a Leibniz, ou Kant a Hegel, verifica-se uma ambição de descobrir, através do pensamento puro, todo significado e configuração do mundo, ao menos como ele é passível de ser percebido por nós.

Nas obras da maioria desses filósofos e cientistas, encontra-se a crença de que o mundo é racional e explicável, afinal, tanto ele quanto nossa mente foram criados através de um Deus racional. Nesse sentido, o desejo de se compreender o mundo, não passa de uma ambição de, mentalmente, tomar o lugar de Deus e testemunhar o mundo pelo lado exterior. Essa necessidade de construir uma teoria científica, a qual pudesse esclarecer o mundo, está intimamente ligada com a busca por conhecer Deus, uma procura pelo absoluto, pelo entendimento do universo através de uma realidade eterna e objetiva.

A ideia de que o conhecimento objetivo deve ser sobre alguma coisa que não as aparências, trazem consigo a presunção de que é possível imaginar uma visão ou uma imagem do mundo que é de alguma forma mais verdadeira do que as visões de observadores humanos. Essa visão não estaria limitada às visões incompletas e incompletamente confiáveis de observadores presentes na terra, mas tal visão só seria possível através de algum ser imaginário que estivesse fora do mundo e se acreditássemos nessa possibilidade, de uma visão externa, seriamos levados a identificar o conhecimento objetivo como conhecimento de mundo absoluto por trás das aparências. Qualquer outro conhecimento é, na melhor das hipóteses, incompleto e deturpado pela subjetividade.

As leis que procuram retratar uma realidade ideal da objetividade frente a exterioridade, não podem ser consideradas como regras, elas apenas nos dão uma ilusão do conhecimento, pois as leis não mudam, mas os fenômenos sim, e através dos milhões de anos que compreendem a história do mundo, várias foram as ocorrências que demonstraram a instabilidade do universo, de certo modo, podemos dizer que esses modelos que regem a vida humana, fazem sentido num corte no espaço e tempo que estamos vivenciando. 


\section{Referências}

BERTALANFFY, Ludwig von. General System Theory: Foundations, Development, Applications. New York: George Braziller, 1968.

BHASKAR, Roy - A realist theory of science. Londres: Verso, 2008.

CILLIERS P. Complexity and postmodernism: understanding complex systems. Routledge, London, 1998.

CILLIERS P. Why we cannot know complex things completely. Emergence, 2002.

CILLIERS P. Complexity, deconstruction and relativism. Theory Cult Soc, 2005.

DEWITT, Richard. Worldviews - An introduction to the history and philosophy of science. Blackwell, 2004.

HEGEL, Georg W. F. Enciclopédia das ciências filosóficas em compêndio - A ciência da lógica. São Paulo, Loyola, 1995.

HEGEL, Georg W. F. Enciclopédia das ciências filosóficas em compêndio - A filosofia da natureza. São Paulo: Loyola, 1997.

HEGEL, Gerog. W. F. Ciência da Lógica: 3. A doutrina do conceito. Petrópolis: Vozes, 2018.

KANT, Immanuel. Crítica da Razão Pura. 5. ed. Tradução Manuela Pinto e Alexandre Morujão. Lisboa: Fundação Calouste Gulbenkian, 2001.

LLOYD, Seth. The computational universe. In: Information and the nature of reality - from physics to metaphysics. Ed. Paul Davies e N. E. Gregersen. Cambridge: Cambridge University Press, 2010.

NEWTON, Isaac. Princípios matemáticos da filosofia natural. In: Newton e Leibniz. Coleção Os Pensadores. São Paulo: Abril Cultural, 1983.

PRIEST, Graham. Inconsistencies in motion. In: American Philosophical Quarterly, VOL. 22 (4), OUTUBRO DE 1985.

PRIGOGINE, Ilya. O fim das certezas - tempo, caos e as leis da natureza. São Paulo: UNESP, 1996.

PRIGOGINE, Ilya. Is future given? New Jersey: World Scientific, 2003.

PRIGOGINE, Ilya; STENGERS, Isabelle $-A$ nova aliança. A metamorfose da ciência. Brasília: Universidade de Brasília, 1984. 
12 | Opinião Filosófica, V. 11, Dossiê - Teoria do Objeto na Lógica de Hegel

ROSEN, Robert - Life itself - a comprehensive inquiry into the nature, origin and fabrication of life. New York: Columbia University Press, 1991.

Recebido em: 09/03/2020.

Aprovado em: 17/03/2020. 